\title{
An Overview on Zeolite Shaping Technology and Solutions to Overcome Diffusion Limitations
}

\author{
Rogéria Bingre ${ }^{1}$, Benoît Louis ${ }^{1, *}$ and Patrick Nguyen ${ }^{2}$ \\ 1 ICPEES-Institute de Chimie et Procédés pour l'Energie, l'Environment et la Santé, \\ Energy and Fuels for a Sustainable Environment Team, UMR 7515 CNRS—Université de Strasbourg-ECPM, \\ 25 rue Becquerel, F-67087 Strasbourg CEDEX 2, France; rpamaral@unistra.fr \\ 2 Saint-Gobain C.R.E.E, 550 Avenue Alphonse Jauffret, BP 224, 84306 Cavaillon CEDEX, France; \\ Patrick.Nguyen@saint-gobain.com \\ * Correspondence: blouis@unistra.fr; Tel.: +33-3-6885-2766
}

Received: 19 March 2018; Accepted: 16 April 2018; Published: 18 April 2018

\begin{abstract}
Synthetic zeolites are widely used as catalysts/carriers for many petrochemical reactions and in refining processes. These materials are usually synthesized in a powder form and must be shaped prior to use in industrial reactors. This review presents the state-of-the-art of the zeolite shaping technology describing the main modifications induced by the interactions between the zeolite and the binder. Additionally, a strategy is presented to overcome the diffusion limitations associated to the microporous structure of zeolites, consisting in the introduction of hierarchical porosity in the binder. Several developments in the field of hierarchical aluminas are summarized in this article, highlighting the possibility to design different ordered/disordered mesoporous and macroporous structures.
\end{abstract}

Keywords: zeolites; shaping; hierarchical porosity; alumina; binder

\section{Zeolite Properties}

The term zeolite was defined in 1756 by the Swedish mineralogist Axel F. CrØnstedt [1] after heating the mineral stilbite with a blowpipe flame, while observing the release of large amounts of

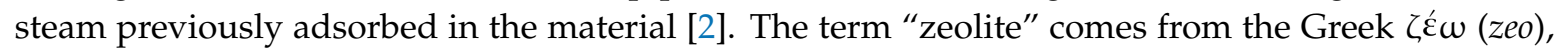

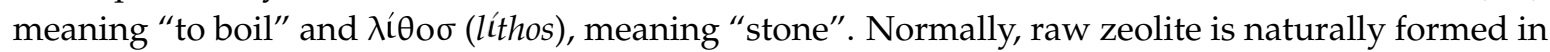
the Earth's crust under particular hydrothermal and geological conditions, but it is rarely pure, often being contaminated by other minerals, metals, quartz, or other zeolite structures. For this reason, their industrial application is excluded, being mostly used in geological museums, jewellery, or as construction materials.

Fortunately, these materials can also be synthesized. Last century, the industry has been using synthetic zeolites as catalysts/carriers in several petrochemical reactions and in refining processes since the 1950s. Their framework is constructed by the association of $\mathrm{TO}_{4}$ tetrahedra, most commonly $\left[\mathrm{SiO}_{4}\right]^{4-}$ or $\left[\mathrm{AlO}_{4}\right]^{5-}$ linked by shared oxygen atoms; however, other elements, such as $\mathrm{B}, \mathrm{P}, \mathrm{Ge}, \mathrm{Ga}, \mathrm{Ti}$, or Fe may also be incorporated. Zeolites are crystalline microporous materials, and the presence of water and cations (alkalis, alkaline-earths) allows the compensation of the negative charges generated by the presence of $\mathrm{Al}$, giving birth to the general formula:

$$
\mathrm{M}_{\mathrm{x} / \mathrm{n}}\left(\mathrm{AlO}_{2}\right)_{\mathrm{x}}\left(\mathrm{SiO}_{2}\right)_{\mathrm{y}} \cdot \mathrm{zH}_{2} \mathrm{O}
$$

with $\mathbf{M}$ being the compensating cation of the negatively charged framework $\left(\right.$ as $\mathrm{H}^{+}$or $\mathrm{Na}^{+}$), $\mathbf{y} / \mathbf{x}$ the $\mathrm{Si} / \mathrm{Al}$ ratio (SAR), and $\mathbf{z}$ the number of molecules of water. Based on Löewenstein's rule [3] Al-O-Al linkages are not allowed and, therefore, $\mathbf{y} / \mathbf{x} \geq 1$. 
Figure 1 shows ANA zeolite crystals which can be found in nature, but also synthesized in laboratories; it is worthy to mention that the crystal sizes differ, at least, from two orders of magnitude due to geological time scales on one hand, and a few days on the other.
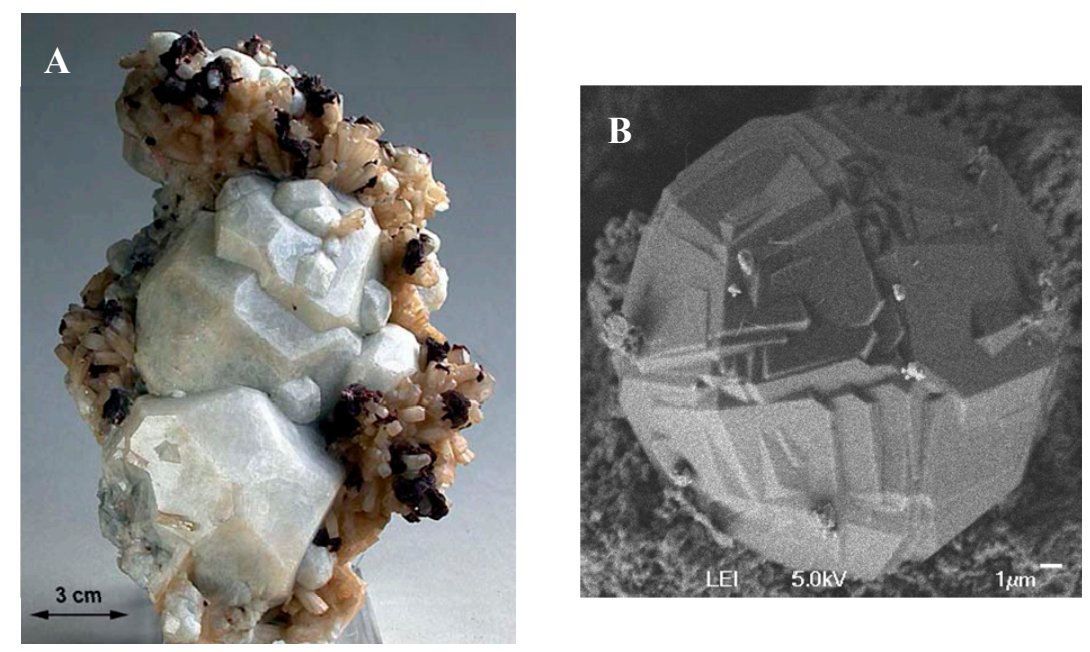

Figure 1. Analcime zeolite, natural mineral (A); as-synthesized in our laboratory (B) [4].

These peculiarities render zeolites so important in industry, since it creates well-defined channels and cages of molecular dimensions. Typically, zeolite pores have diameters up to $2 \mathrm{~nm}$ [5] and, so-called micropores, and due to their regular openings of determined size they allow small molecules to diffuse straight through, but trap larger ones, acting as molecular sieves, leading to this other common name for zeolites. Normally, those pores are filled with water and other cations, but they can be easily exchanged by other positively-charged ions. There are currently 235 distinct zeolite structures known (228 ordered structures and seven structures with partial disorder) possessing peculiar physical and chemical properties, which have been allocated unique three-letter codes by the International Zeolite Association, such as MFI, BEA, and FAU (Figure 2). Among them, nearly twenty are implemented at the industrial scale, but only five constitute the so-called "big five": MFI, BEA, MOR, FAU, and FER.

\section{$\mathbf{a}$}

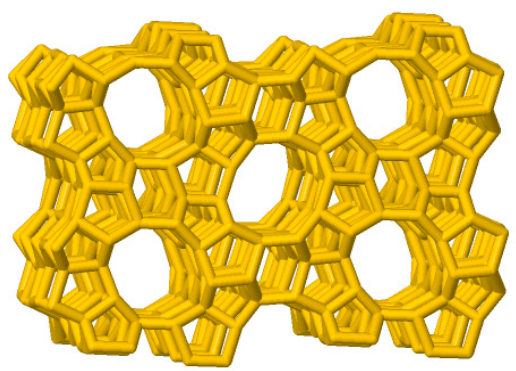

b

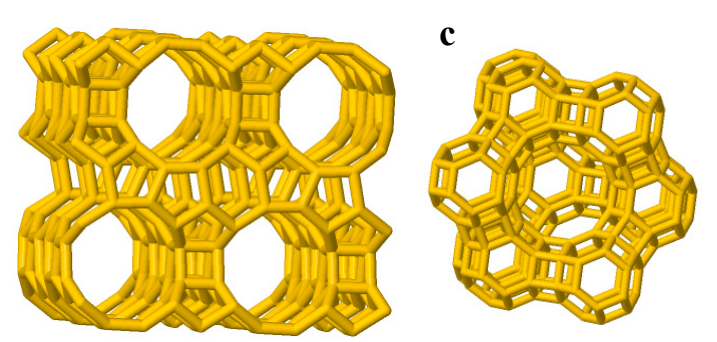

Figure 2. Three members of the "Big Five": (a) MFI a 10-MR zeolite with a pore diameter of $5.5 \AA$; (b) BEA a 12-MR zeolite with a pore diameter of $6.0 \AA$; and (c) FAU a 12-MR zeolite with pore diameter of $7.4 \AA$ [6]. 


\section{Applications of Zeolites}

Zeolites are applied in several processes, such as cracking, isomerization, hydrocarbon synthesis, synfuel production, refining, and production of chemicals. These processes involve the use of fixed-bed or fluidized-bed reactor technologies. Fluidized-bed reactors are required for processes like fluid catalytic cracking (FCC) and oxychlorination of ethane to chloroethane, for example, where it is necessary to lift the catalyst material in its fluid state. Although synthetic zeolites are obtained in the form of a fine powder the crystallites are too small to be used directly in such kinds of reactor technology. In this way, the catalyst is shaped by spray-drying methods to give birth to abrasion-resistant particles of 60 to $100 \mu \mathrm{m}$ diameter. Additionally, in cases where the process requires a fixed-bed reactor technology, the problem relies on the fact that powder exhibits poor mechanical strength that can lead to damage or degradation of the catalyst, thus creating fines at the reactor outlet. Indeed, the presence of small particulates can lead to dramatic consequences on both the reaction and the equipment. The required mechanical strength may be conferred by shaping the zeolite (Figure 3), for example in a pellet or extrudated form: the best choice being conditioned by hydrodynamic considerations. Hence, mass and heat transfer limitations and pressure drop issues have to be fixed to perfectly design the reactor. The final material should possess significant physical strength and, therefore, being abrasion and fracture resistant during loading and transport. Reactions that are performed in this case are, for example, the reforming of naphtha fraction and toluene disproportionation.

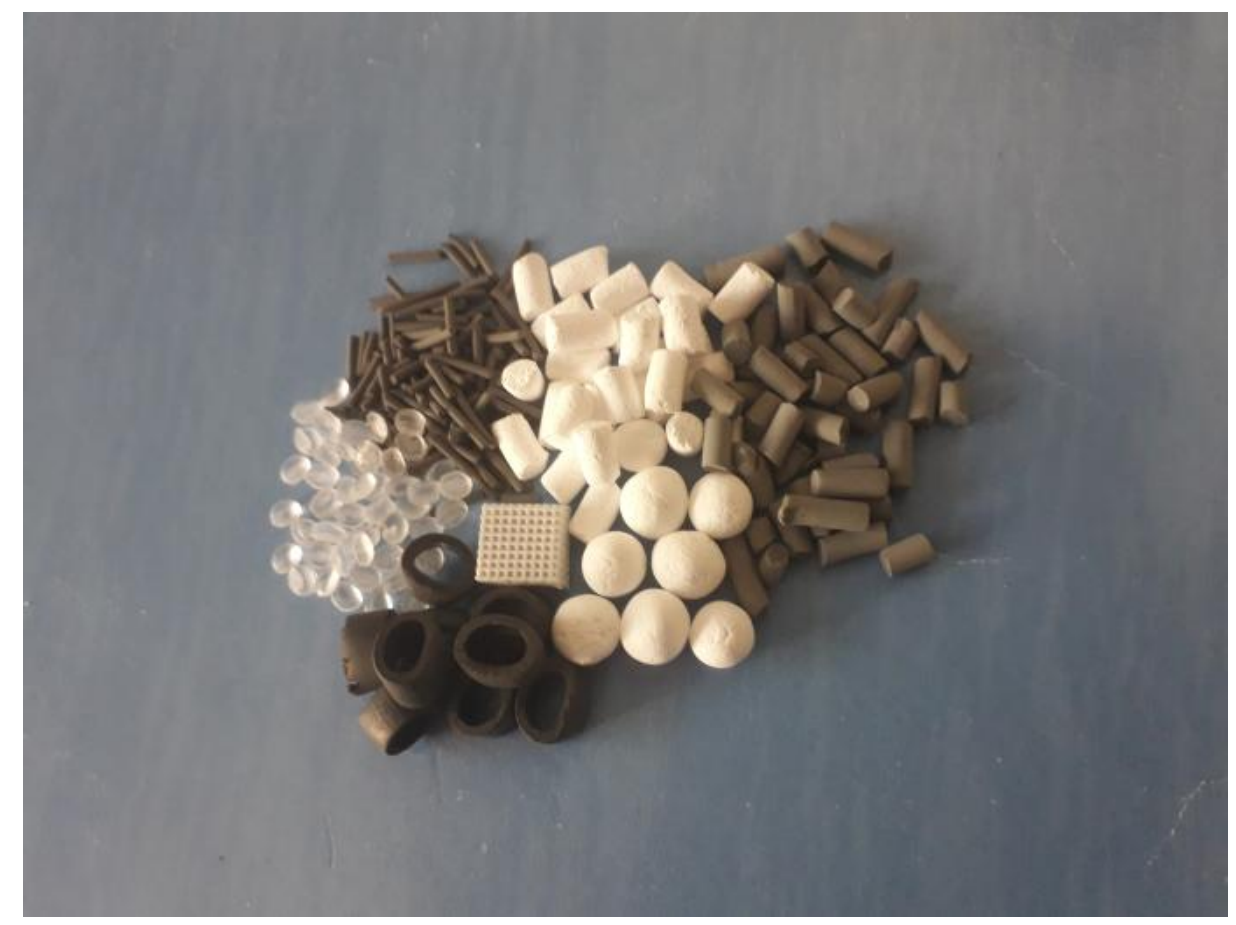

Figure 3. Different catalyst morphologies.

The zeolite shaping is performed in the presence of a binder or matrix. Common binders are clays, such as kaolin, attapulgite, boehmite, aluminas, and/or silicas or combinations of these materials. Those additives have to be added in quantities which are generally higher than $20 \%$ in weight to reach the desired mechanical strength, forming a homogeneous and plastic mixture. Then, the latter mix can be extruded in a desired shape, dried to evaporate the water and calcined at high temperature to confer the appropriate targeted mechanical and textural properties. However, one should consider that the high-pressure forming process can alter the physicochemical properties if the pore size is too large, like mesoporous materials, or if the framework is fragile. Figure 4 presents the extrusion process of a zeolite/binder mixture and the final centimeter-sized cylinders. 


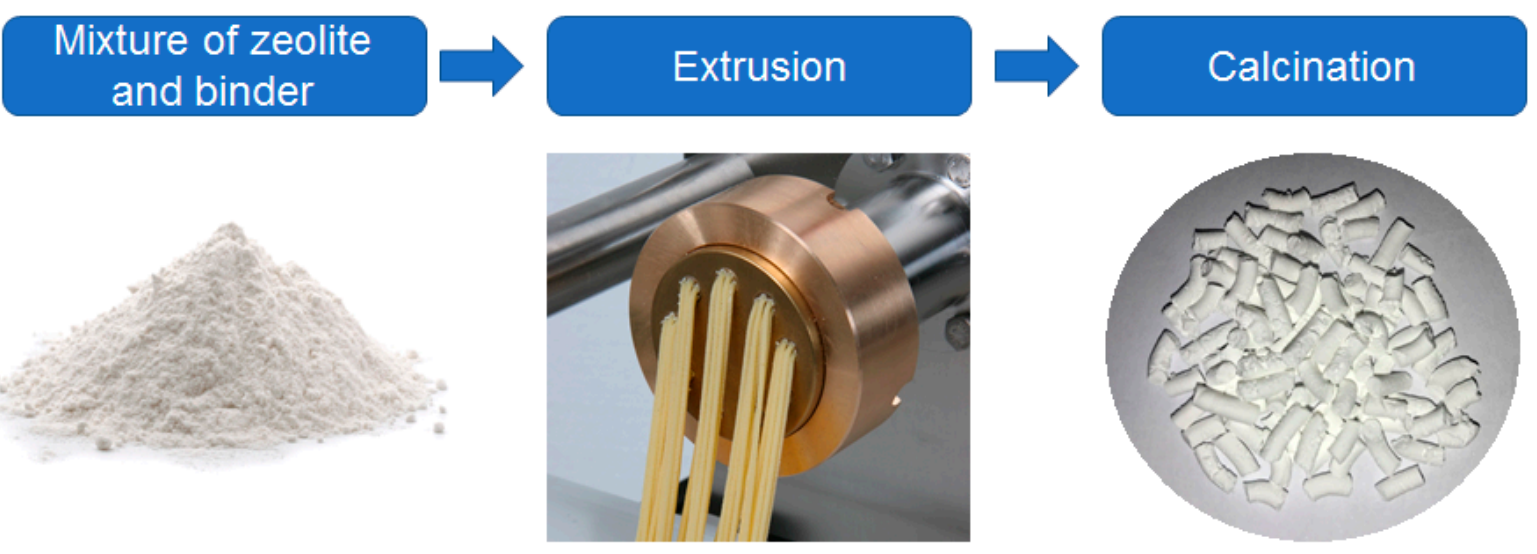

Figure 4. Scheme of the extrusion process.

\section{Strategies to Produce Zeolite Bodies}

\subsection{Silica and Alumina Binders}

Several studies devoted to the different strategies to produce zeolite extrudates are given in the following paragraphs. First, Perego et al. [7] reported a procedure to design an extruded catalyst based on silica/alumina gel. In this approach the gel was blended with boehmite or pseudoboehmite prior to the ageing step (occurring after extrusion). To facilitate the extrusion step, methyl cellulose and glacial acetic acid were added. The authors observed a mechanical strength of 90 to $280 \mathrm{~kg} / \mathrm{cm}^{2}$ and a specific area close to $500 \mathrm{~m}^{2} / \mathrm{g}$.

However, the addition of binders can significantly alter the zeolite properties, in terms of structure or acidity. For instance, Chu et al. [8] measured a quasi-inexistent acidity with an activity similar to high silica-containing ZSM-5 zeolite with a $\mathrm{Si} / \mathrm{Al}>1600$ by reacting the same with a solid binder in the presence of water. Those binders were materials with high aluminum content, such as alumina, along with silica, titania, silica-alumina, etc. They claimed to improve the activity of crystalline silicate materials with little or no acidity by mixing them with the aforementioned materials for acid catalysis purposes. By considering the influence of active sites, Martin et al. [9] performed a bounding system between HZSM- 5 and boehmite. They observed that boehmite, although partially neutralizing Brønsted acid sites, can induce supplementary weak and strong Lewis acid sites. Additionally, it can act as a catalyst for coke formation, preserving the sites of the zeolite activity, thus leading to higher alkene yields in n-butane cracking reaction.

Wu et al. [10] performed a study aiming to analyze the influence of alumina and silica binders on the acidity of ZSM-5 and Y zeolites. Regarding alumina, an increase of Brønsted acid sites was observed for alumina-bound $Y$ that might be explained by the reaction of free $\mathrm{SiO}_{2}$ (non-frame silica) present in the zeolite with the binder at high temperature, either during calcination or by an easier insertion of alumina into Y zeolite than ZSM-5. In contrast, Liu et al. [11] observed a decrease in the total acidity after blending ZSM-5 with colloidal silica, due to possible neutralization. Wu et al. [10] also demonstrated, for silica-bound zeolites, especially for $\mathrm{Y}$ zeolite, a general decrease of the total acidity. Although the same phenomenon between silica from the binder and extra-framework species forming new Brønsted acid site occurred, the presence of sodium ions in LUDOX HS-40 (silica binder used) may have neutralized them. This was corroborated by Lee et al. [12] after blending HZSM-5 zeolite with silica, alumina, and/or aluminophosphate solution together with hydroxylethylcellulose. Upon testing the samples in the conversion of methanol to propylene, they also reached the conclusion that the best procedure would be the addition of silica or alumina with aluminophosphate solution, conferring high bulk crush strength and similar propylene selectivity to that achieved over HZSM-5. In those three studies, both pore volume and surface area of zeolite were observed to diminish after the binder addition. 
Likewise, Kasture et al. [13] established correlations between BEA zeolite composition with different percentages of alumina binder along with the shape of the final composite catalyst and the performance in isopropylation of benzene. An increase in benzene conversion was achieved when the content of alumina was raised being caused by an increase in the total acidity of the catalyst with alumina. The catalyst pellet appeared to be the best formulation over catalyst extrudates (Figure 5).

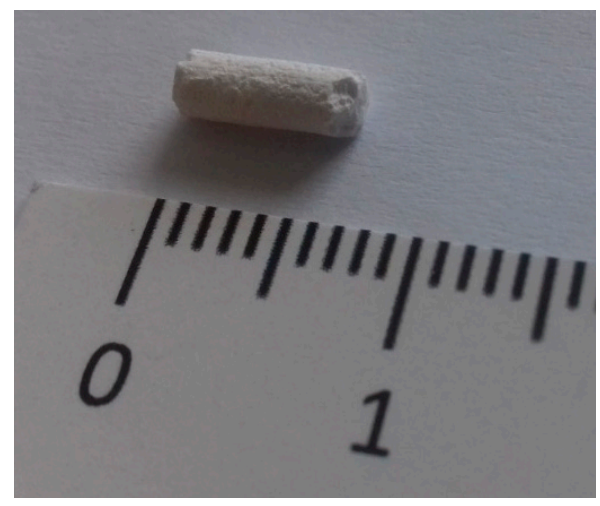

Figure 5. Homemade catalyst extrudate pellet.

A new concept appeared along with the study of Kong et al. [14] devoted to the inter-crystalline mesoporosity generation by the addition of binders. They observed an increase of mesopores created by intercrystalline voids of alumina crystallites leading to a better performance of Ni/ZSM- 5 zeolite in the hydrodeoxygenation of cyclohexanone. However, it also caused a lower metal dispersion hiding the conversion of this compound, hence leading to set an optimal loading of $30 \mathrm{wt} \%$ of the alumina binder. For the same reaction and catalyst, Du et al. [15] reached the same conclusions: the total mesopore volume and average pore diameter were the highest for an extruded catalyst with alumina, although the surface area and micropore volume diminished after the addition of binders. Pérez-Uriarte et al. [16], while investigating the effects of bentonite and boehmite on the performance of ZSM-5 zeolite in the transformation of DME into olefins, observed that although the BET surface area and microporous volume diminished after the addition of the binders, it conferred a remarkable volume of mesopores and higher acidity, but with weak acid strength. This led to high selectivity towards propylene at low conversion level.

An alternative to alumina binder has been proposed by several groups that consists in modified pseudo-boehmite by adding $\mathrm{P}$ through phosphoric acid to the binder, forming an amorphous AlPO phase [17-20]. Freiding et al. confirmed that aluminum phosphate-bound zeolite extrudates exhibit no acidity due to interaction of phosphate species with the acid sites. However, the original acidity could be restored by means of repeated ion-exchange-calcination steps. This characteristic was considered to be essential to study as, in the mechanism of methanol to propylene, the key step for an effective conversion of methanol lies in controlling the reaction at the olefin formation stage, where the acidity of the catalyst plays a crucial role. Due to that, the authors analyzed the advantages of using aluminum phosphate as a binder for ZSM-5. Although the micropore volume decreased after the addition of the binder, it created a macroporous system in the matrix, which may be beneficial to avoid pore diffusion resistance. Likewise, since no insertion of $\mathrm{Al}$ species from the binder in the zeolite framework occurs, it allowed an optimization of the $\mathrm{Si} / \mathrm{Al}$ ratio. Therefore, the results showed an improved selectivity in $\mathrm{C}_{2}-\mathrm{C}_{4}$ olefins, especially towards propylene.

In terms of silica as a binder, its nature (acid, basic, or neutral) can strongly influence the acidic properties of the zeolite. Liu et al. [11] observed that HZSM-5 extruded with colloidal silica showed higher acidic properties, but also rapid deactivation attributed to the coke formed over the zeolite catalyst; which may block the acid sites and channels. It could also be attributed to changes in the mesoporous structure during alkali treatment. Whiting et al. [21] suggested that 
although $\mathrm{SiO}_{2}$ lacks acid sites able to take part in acid-catalyzed processes, its intimate contact with impregnated zeolite can induce solid-state ion exchange, with loss of Brønsted acidity as a result of zeolite framework dealumination.

In contrast, if the objective is to maintain the acidity of the catalyst, the binding of zeolites with silica can be made as shown by Bowes [22] with ZSM-5 zeolite, but Ghosh et al. [23] developed a method for producing Ge-ZSM-5 zeolite shaped body with a silica binder. In this case, the silica binder was comprised of solid silica and colloidal silica containing other non-silica oxides, such as $\mathrm{Al}_{2} \mathrm{O}_{3}, \mathrm{MgO}, \mathrm{Fe}_{2} \mathrm{O}_{3}, \mathrm{CaO}$, etc. The silica binder was used because it is barely acidic, which provides no significant acid-cracking side reaction(s) producing less light hydrocarbons, thus resulting in an enhanced selectivity towards higher hydrocarbons. It can be included an extrusion aid of a partially hydrolyzed polyvinyl alcohol to the zeolite and binder mixture since it has been shown that this compound greatly enhanced the mechanical or crush strength of the extrudate made from the zeolite and silica binder.

However, this is not viable in the case of bi-functional hydrocracking catalysts where the metal dispersion is known to be crucial. With that in mind, Keville et al. [24] performed the preparation of high-silica Y zeolite with improved resistance to the alumina binder. It involved the zeolite treatment to reduce the amount of silanol groups prior to the blend with alumina binder and water followed by extrusion. In the latter case, Y zeolite with high silica content and high mechanical resistance provided by alumina was obtained. Table 1 presents an overview of alumina and silica binders, their characteristics, and their impact on the overall acidity.

Table 1. Selected examples of alumina and silica binders, their characteristics, and influence on the zeolite acidity.

\begin{tabular}{|c|c|c|c|c|c|}
\hline Reference & Catalyst & Binder & $\mathrm{S}_{\mathrm{BET}}\left(\mathrm{m}^{2} / \mathrm{g}\right)$ & $\begin{array}{l}\text { Mechanical Strength } \\
\left(\mathrm{kg} / \mathrm{cm}^{2}\right)\end{array}$ & Influence in Acidity \\
\hline [7] & $\begin{array}{l}\text { Amorphous } \\
\text { silica/alumina }\end{array}$ & $\mathrm{AlO}(\mathrm{OH})$ & 608 & 249 (10 wt \% binder) & \\
\hline [9] & ZSM-5 & $\begin{array}{l}\mathrm{SiO}_{2} \text { or } \\
\mathrm{AlO}(\mathrm{OH})\end{array}$ & & & $\begin{array}{c}\text { Acidity maintained } \\
\text { with } \mathrm{SiO}_{2} \text {, but } \\
\text { decreased with } \\
\mathrm{AlO}(\mathrm{OH})\end{array}$ \\
\hline [11] & ZSM-5 & $\mathrm{SiO}_{2}$ & $210-350$ & & Decreased \\
\hline [12] & ZSM-5 & $\begin{array}{l}\mathrm{SiO}_{2} \text { or } \\
\mathrm{AlO}(\mathrm{OH}) \\
\text { or } \mathrm{AlPO}\end{array}$ & $320-450$ & $\begin{array}{c}1.4\left(10 \mathrm{wt} \% \mathrm{SiO}_{2}\right)-4.8 \\
(20 \mathrm{wt} \% \mathrm{AlPO})\end{array}$ & Decreased \\
\hline [13] & BEA & $\mathrm{Al}_{2} \mathrm{O}_{3}$ & $400-500$ & & Increased \\
\hline [14] & ZSM-5 & $\mathrm{Al}_{2} \mathrm{O}_{3}$ & $235-275$ & & Decreased \\
\hline [15] & ZSM-5 & $\begin{array}{l}\mathrm{Al}_{2} \mathrm{O}_{3} \text { or } \mathrm{SiO}_{2} \\
\text { or kaolin }\end{array}$ & $200-260$ & & Decreased \\
\hline [16] & ZSM-5 & $\mathrm{Al}_{2} \mathrm{O}_{3}$ & $200-300$ & & Decreased \\
\hline [18] & ZSM-5 & AlPO & $315-370$ & & Decreased \\
\hline [19] & ZSM-5 & AlPO & & $\begin{array}{c}81 \text { ( } 25 \text { wt \% binder })-907 \\
\quad(75 \text { wt \% binder })\end{array}$ & $\begin{array}{l}\text { Maintained after } \\
\text { ion-exchange }\end{array}$ \\
\hline [21] & ZSM-5 & $\mathrm{SiO}_{2}$ or $\mathrm{Al}_{2} \mathrm{O}_{3}$ & 350 & & Decreased \\
\hline
\end{tabular}

\subsection{New Binder Systems}

As seen previously, silica and alumina are the most common binders to shape catalyst bodies (Table 1). They are cheap and expected to induce beneficial effects in the catalytic properties. However, other ways for shaping zeolites have been studied. In 1992, Plee [25] used siliceous earth as a binder, to produce a paste with the zeolite powder together with an aqueous solution formed by the dissolution of hydrated alumina in sodium hydroxide. The shaped zeolite was obtained by means of extrusion, but other methods could also be used to produce agglomerates. The authors assessed the feasibility of this process for $\mathrm{A}, \mathrm{X}$, and $\mathrm{Y}$ zeolites in petrochemistry, for air conditioning in cars or as dessicants in insulating double windows. 
Additionally, Timken [26] prepared a method to design titania-bound zeolite catalysts. It consists of a homogeneous mixture of ZSM-5, low acidity titania binder and an aqueous slurry of titanium oxide hydrate to provide a shapable and extrudable mass. These catalysts exhibit lower binder activity than alumina-bound zeolites, which is useful in hydrocarbon conversion processes with reduced coke formation, extending the catalyst lifetime. After calcination, the material can be subjected to other operations, such as alkaline exchange, dealumination, steaming, and impregnation with catalytically-active metal(s). It is noted that low-acidity refractory oxide binders, such as titania, do not interact with molecular sieves (zeolite) to enhance the acid catalysis activity but they maintain their structural integrity at low $\mathrm{pH}$, thus implying possible treatment with an acid to modulate dealumination.

Verduijn [27] suggested a process for producing shaped zeolites without any need for binder addition. For that, silica binder can be converted into zeolite phase (MFI, KFI, FAU, BEA, etc.) by ageing the bound zeolite in an ionic solution. This solution should contain hydroxyl anions with an initial molar ratio of $\mathrm{OH} / \mathrm{SiO}_{2}$ up to 1.2. This discovery may solve the problem of obtaining a bound zeolite aggregate with lower adsorption properties than the zeolite powder. Note that binder-free refers to zeolites containing less than $10 \mathrm{wt} \%$ (based on the total weight) of non-zeolitic binder. The preparation procedure occurs, therefore, in an usual way: synthesis of a zeolite mixture and ageing prior to crystallization. The as-obtained solid is washed, dried, and optionally calcined to produce zeolite powder; the zeolite powder is mixed with a silica sol together with an extrusion aid to form a thick, smooth paste. The paste is then extruded to form silica-bound extrudate which is dried and calcined; the extrudates are mixed with the ionic solution, aged in autoclave, washed, dried, and calcined.

Recently, some studies have highlighted the fact that the introduction of a binder in the zeolite led to form agglomerates which can significantly reduce intercrystalline diffusivities and also affect the adsorption equilibrium; indeed these materials demonstrated different adsorption properties for hydrocarbons. Sun et al. [28] evaluated the effects of the binder in the adsorption of $n$-paraffins on 5A molecular sieves. Experiments realized under the same conditions revealed that binderless $5 \mathrm{~A}$ zeolite pellets led to higher adsorption capacities for four paraffins than pellets (with a binder). The authors attributed this difference to two aspects: a dilution effect, as well as a main aperture blocking effect. It is also possible to directly synthesize zeolite monoliths; however, they exhibit reduced mechanical strength. The advantage relies on the fact that the addition of binders enhances the risk of pore blockage and hindered accessibility to the active sites. Similarly, Zhang et al. [29] aimed to develop one-pot hydrothermal synthesis of monolithic zeolites in the absence of any organic template and binder that might avoid the high-temperature template removal and post-molding process. In addition, this strategy should allow the direct use of the zeolite products. MOR monolith was prepared by an unconventional acid hydrolysis route using neither organic templates nor binders. It was observed that TEOS as the silica source was the key factor for the generation of the monolith. The same zeolite used to make monoliths was also mixed with colloidal silica as binder. A catalyst with lower surface area and pore volume was obtained. This can be explained by partial pore blockage due to the addition of the binder as discussed in the former section. The MOR-monolith exhibited the largest micropore size and maximum micropore content among all as-prepared samples.

In the previous section, the influence of bentonite and boehmite was reported by Pérez-Uriarte et al. [16]. Likewise, Jasra et al. [30] studied the effect of a clay binder, as bentonite and attapulgite on the sorption and catalytic properties of zeolite X, Y, and MOR pellets. An increase in the heat of adsorption values upon pelletization was highlighted, which may be explained by the migration of clay cations within the zeolite cavities, thus decreasing the surface activity. This means, solid-state ion-exchange of $\mathrm{Na}^{+}, \mathrm{Mg}^{2+}$ in the zeolite may occur, thus reducing the Brønsted acid site density. The same conclusion was reached by the group of Dorado et al. [31-33] while studying the influence of bentonite on the acidity and performance of BEA and ZSM-5 zeolites.

Shams et al. [34] prepared 5A zeolite monolith granular extrudates using firstly metakaolin as silica and alumina source, kaolin and carboxymethylcelullose (CMC) as binder agents. Different 
percentages of those compounds were used, with a higher purity and better adsorption properties when $30 \mathrm{wt} \%$ of kaolin and small amounts of CMC were achieved. The authors attributed the effect on the adsorption properties to the de-clogging of the pores caused by the gasification of CMC during the final calcination of the extrudates. However, data related to the mechanical resistance of the material were missing in this study [34]. Uphade et al. [35] presented a shaped Ga-ZSM-5 zeolite. In order to extrudate the catalyst, La modified kaolin was added as a binder in a weight percentage comprised between $30 \%$ and $35 \%$. The authors noticed that the zeolite binder catalyst led to appreciable alkane conversion, to good overall yield in aromatics and to lower deactivation rate than other catalysts containing Ga and/or silica or alumina as binders. However, Du et al. [15] showed that the specific surface area and micropore volume diminished after kaolin binder addition. Its structure is ruled by weak van der Waals interactions that can be cracked by water entering the interlayer, potentially reducing ZSM-5 pore blocking.

A flash-calcined hydrotalcite (HT) binder for MFI zeolite was suggested by Lee et al. [36] as a strategy to maintain the acidity. For that, basic trihydroxide was calcined for a few seconds to form flash-calcined HT. This product was blended to MFI zeolite in quantities up to $20 \mathrm{wt} \%$ along with a minimal quantity of water to make a paste for granulation. The crushing strength of the MFI zeolite granule was measured and found comparable to commercially available MFI granules containing alumina as a binder. The authors confirmed that the MFI zeolite granule prepared using flash-calcined $\mathrm{HT}$ could be used as an acid catalyst. In contrast, the use of $\mathrm{SiO}_{2}$ and $\mathrm{Al}_{2} \mathrm{O}_{3}$ failed in either shaping the spherical granule or in obtaining sufficient mechanical strength. According to TPD measurements, the acidity changed when alumina was used, but not when flash-calcined HT was used as a binder.

In order to evaluate the performance of the catalyst, 1-butene isomerization and MTO reactions were selected. The results, when compared with a MFI reference catalyst, suggested no influence of the flash calcined HT as a binder in the first-mentioned reaction. In the case of MTO, although the conversion was maintained, a slightly different product distribution was obtained, being attributed to pore blockage by the HT. In conclusion, there were no adverse effects due to the presence of flash-calcined HT in the granule and the catalytic activity could be preserved.

Zeolites can also be shaped by means of a hydraulic binder as affirmed by Bazer-Bachi et al. [37]. The hydraulic binder can be high-alumina cement, sulphoaluminate cements, plaster, cements containing phosphate, blast furnace slag cements and mineral phases selected from alite $\left(\mathrm{Ca}_{3} \mathrm{SiO}_{5}\right)$, belite $\left(\mathrm{CaSiO}_{4}\right)$, alumina-ferrite, tricalcium aluminate $\left(\mathrm{Ca}_{3} \mathrm{Al}_{2} \mathrm{O}_{6}\right)$, and calcium aluminates, such as monocalcium $\left(\mathrm{CaAl}_{2} \mathrm{O}_{4}\right)$ and calcium hexoaluminate $\left(\mathrm{CaAl}_{12} \mathrm{O}_{18}\right)$. The material obtained had $10-95 \%$ of zeolite; $0-5 \%$ of source of silica; $0-7 \%$ of one organic adjuvant; and $1-20 \%$ of hydraulic binder.

One advantage remains the successful design of a material with improved mechanical strength and high thermal resistance, being potentially useful for processes involving steam or solvents. In this process there is no need for calcination step after the shaping that has no effect on the properties of the final material and can be carried out irrespectively of the zeolite content. Table 2 presents an overview of alternative binders used for zeolite shaping along with some remarks observed during the studies.

Table 2. Summary of the alternative binder strategies.

\begin{tabular}{|c|c|c|c|}
\hline Reference & Zeolite & Binder & Observations \\
\hline [25] & $\mathrm{A}, \mathrm{X}$ and $\mathrm{Y}$ & Siliceous earth & \\
\hline [26] & ZSM-5 & Titania & $\checkmark$ Lower binder activity \\
\hline$[27,29]$ & Several & Binder-free & $\begin{array}{l}\checkmark \text { Adsorption properties similar to } \\
\text { zeolite powder } \\
\checkmark \text { No evidence of pore blocking }\end{array}$ \\
\hline [30-33] & $\begin{array}{l}\text { X, Y, MOR, } \\
\text { BEA, ZSM-5 }\end{array}$ & Bentonite and attapulgite & $\begin{array}{l}\times \text { Solid-state ion-exchange of } \mathrm{Na}^{+}, \mathrm{Mg}^{2+} \text { : } \\
\text { decrease in Brønsted acid site density } \\
\checkmark \text { Preservation of the acidity }\end{array}$ \\
\hline [36] & MFI & Hydrotalcite & $\begin{array}{l}\checkmark \text { Crush strength similar to commercial } \\
\text { MFI granules }\end{array}$ \\
\hline [37] & Several & $\begin{array}{l}\text { Hydraulic binders (cements, } \\
\text { plaster, aluminates, ... ) }\end{array}$ & $\begin{array}{l}\checkmark \text { High mechanical strength } \\
\checkmark \text { High thermal resistance }\end{array}$ \\
\hline
\end{tabular}




\section{Hierarchical Aluminas as a Solution for Diffusion Limitations}

As reported in the previous section, zeolites must be shaped into centimeter-sized bodies to be used in industry, such as in reactors or columns. In some reactions, the diffusion of reactants plays a major role in the activity of the catalyst. Indeed, mass transfer limitations inside the zeolite particle may hamper the catalyst performance. This implies that upon the formation of larger molecules, their diffusion to the pores exit is not facilitated, leading to pore blockage and deactivation of the catalyst by coke formation. When the zeolite is mixed with a binder in order to be extruded, this diffusion problem is amplified, as the possibility of pore blockage by the binder is greater, thus implying that the molecules cannot reach the active sites. Generally, the binder possesses a smaller specific surface area, and rather small or even no pores. This creates a layer between the reaction medium and the surface of the zeolite, inducing severe mass transfer limitations.

$\gamma$-Alumina possess a crystalline framework and can be ascribed to both high thermal stability and moderate Lewis acidity [38]. Additionally, it is known for the high chemical and mechanical stability making it ideal for applications in automotive and petroleum industries, as well as in catalysis [39]. Usually, boehmite appears as the binder of choice for shaping zeolite bodies, while transforming its structure to alumina by calcination. Boehmite is characterized by a low specific surface area, and presence of small pores. This may lead to the problem referred above. It is, therefore, necessary to introduce meso- and/or macropores to guarantee a fast diffusion of the molecules from the reaction medium to the surface of the catalyst (Figure 6).

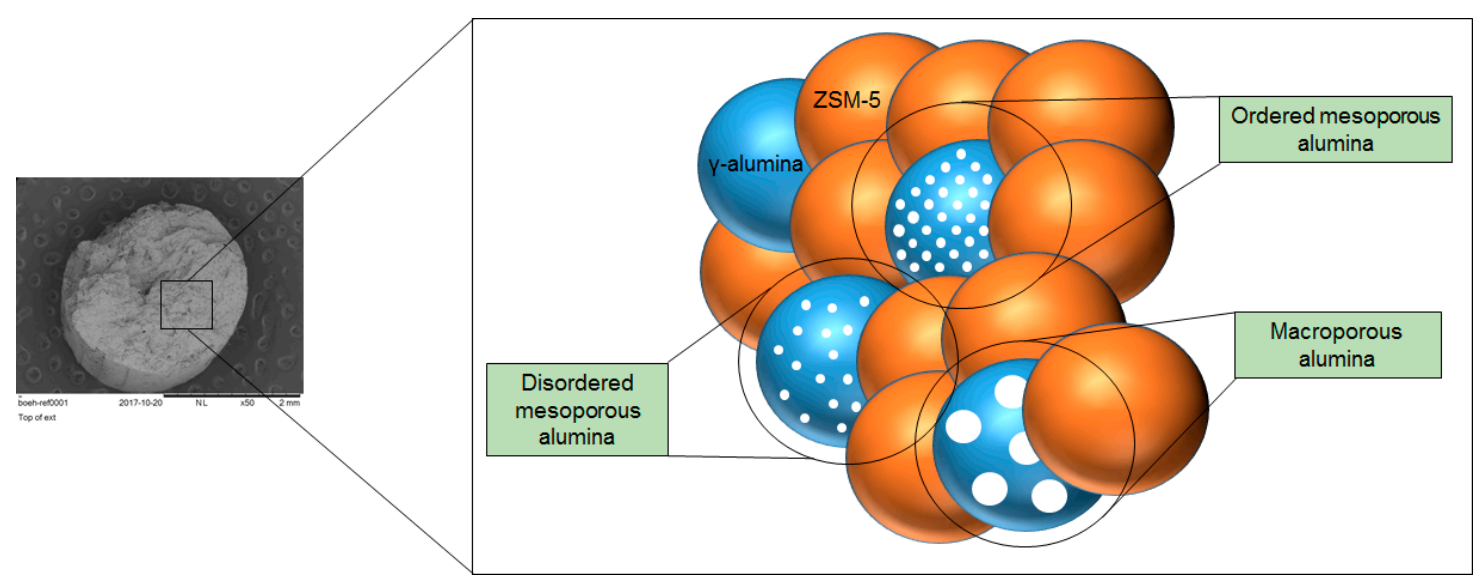

Figure 6. SEM top view image of an extrudate at the $\mathrm{mm}$ scale with a schematic introduction of mesoporous alumina as the binder.

A review of the different strategies to generate hierarchical porosity in alumina found in the literature will be presented in the following paragraphs. It will be mostly focused on the procedures to synthesize those aluminas and the main outcome given.

\subsection{Ordered Mesoporous Aluminas}

To synthesize materials with an ordered mesostructure, several authors proposed the use of amphiphilic block copolymers through an evaporation-induced self-assembly process (EISA) that was first reported by Brinker and Ozin [40,41]. In this case, it consists of an assembly of partially condensed $\mathrm{Al}$ species in the ethylene oxide blocks of the structure-directing co-polymer via weak coordination bonds. Then, a slow solvent evaporation must be performed, as the organic template prevents the mesoporous structure to collapse during the drying step. Finally, through calcination of the powder, the organic template is removed, leaving a void constituting the mesopores (Figure 7).

One of the first studies related to this method involving alumina is the one from Zhao et al. [42]. Indeed, mesoporous aluminas were synthesized by using inorganic aluminum salts (nitrate or sulphate) 
as an alumina source and polyethylene glycol 1540 as an organic template. The samples exhibited a surface area of about $300 \mathrm{~m}^{2} / \mathrm{g}$ and uniform pore size of $6 \mathrm{~nm}$. However, the greatest conclusion of the authors was that mesoporous alumina can be obtained by self-assembly through templating, but not by precipitation from inexpensive inorganic alumina salts.

Later, Yuan et al. [43] proposed an easier procedure using amphiphilic block copolymers, such as Pluronic P123. Combining aluminum isopropoxide with nitric acid, ethanol, and the referred template, drying it slowly at $60{ }^{\circ} \mathrm{C}$ for $48 \mathrm{~h}$ and calcining it for $4 \mathrm{~h}$ at $400{ }^{\circ} \mathrm{C}$, produced samples with a well-ordered and crystalline pore network, evidenced by TEM images and XRD analysis. From nitrogen adsorption-desorption, samples with surface area of $434 \mathrm{~m}^{2} / \mathrm{g}$ and pore diameters up to $6 \mathrm{~nm}$ were formed. The authors highlighted the presence of strong Lewis acidity, provided by aluminum atoms, proving those ordered mesoporous aluminas to be ideal supports for heterogeneous catalysis purposes. The same method was used by Grant et al. [44], but using Pluronic F127. This copolymer formed cage-like mesopores with eight interconnecting cages, having a width of up to $8 \mathrm{~nm}$ and specific surface areas of $338 \mathrm{~m}^{2} / \mathrm{g}$.

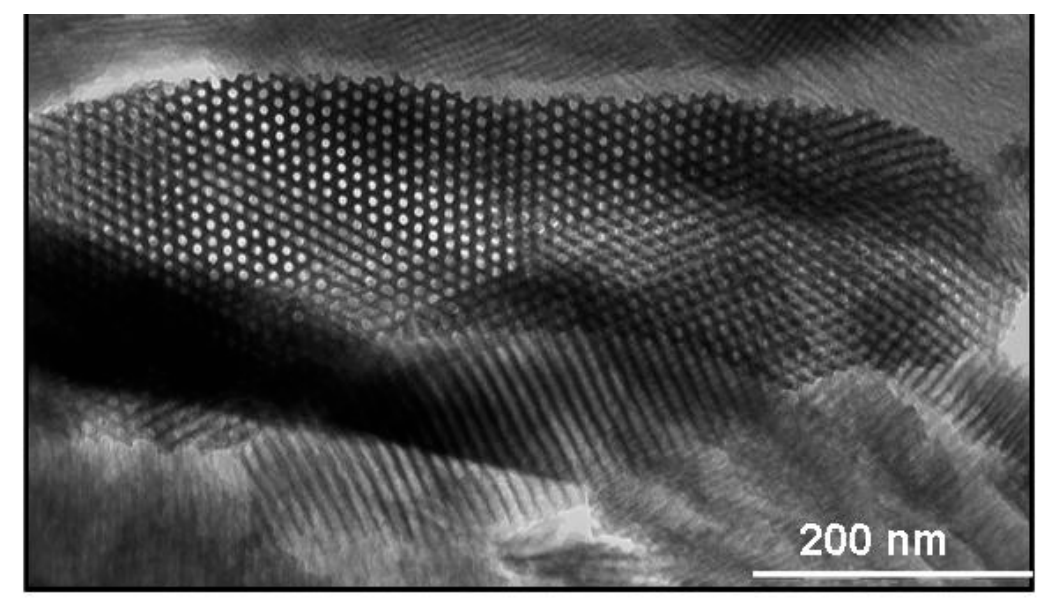

Figure 7. Ordered mesostructure obtained by Hartmann et al. [38].

A slight modification in the synthesis method of mesoporous aluminas by hydrolysis of aluminum isopropoxide with Pluronic P123 was proposed by Wu et al. [45]. In this study, the authors replaced ethanol with water, allowing the introduction of an active component of potassium species to the alumina support after the one-pot synthesis pathway, instead of using common synthesis methods like impregnation. The pore size of the samples prepared was up to $2.9 \mathrm{~nm}$ linked to a surface area of $261 \mathrm{~m}^{2} / \mathrm{g}$. This led to higher biodiesel yields over mesoporous aluminas with higher surface area, pore volume and longer pore sizes, being attributed to reduced mass transfer limitations.

Wu et al. [46] developed a double templating technique consisting in an addition of trimethylbenzene (TMB) with Pluronic P123. In this case, the surfactants were dissolved in ethanol, while aluminum isopropoxide was mixed with $\mathrm{HCl}$ and citric acid. The samples calcined at $500{ }^{\circ} \mathrm{C}$ did not exhibit any diffraction peak, suggesting an amorphous framework, but a further calcination at $900^{\circ} \mathrm{C}$ showed peaks matching with $\gamma$-alumina structure. The authors tentatively explained that alumina oligomers can interact with hydrophilic $\mathrm{PEO}$ segments from Pluronic $\mathrm{P} 123$ by hydrogen-bonding, forming a rigid and robust 2D mesostructure after solvent evaporation at $60{ }^{\circ} \mathrm{C}$ with surface areas up to $309 \mathrm{~m}^{2} / \mathrm{g}$ and pore size of $7.5 \mathrm{~nm}$.

Yuan et al. [47] developed a method to synthesize ordered mesoporous alumina monoliths. Firstly, the EISA method was implemented with hydrolysis of aluminum isopropoxide in the presence of P123 surfactant in ethanol. After a slow evaporation of the solvent and calcination of the powder, it was mixed with acrylamide (cross-linker), ammonium persulfate, and water to form a gel easily shaped into various types of monoliths. TEM images showed highly-ordered hexagonal cylindrical channels, however, the surface area and pore size diminished from pristine to shaped sample (307 to $282 \mathrm{~m}^{2} / \mathrm{g}$ 
and 9.5 to $7.5 \mathrm{~nm}$, respectively). On the other hand, Bejenaru et al. [48] successfully prepared ordered mesoporous aluminas using P123 dissolved in ethanol and hydrochloric acid. In the latter case the aluminum precursor aluminum-tritert-butoxide allowed to generate a $2 \mathrm{D}$ hexagonal pore structure with a surface area of $393 \mathrm{~m}^{2} / \mathrm{g}$ and pore size of $67 \mathrm{~nm}$. However, the sample remained amorphous after calcination.

Liu et al. [49] applied the same method of slow solvent evaporation of gels prepared with an alumina source and P123 as a template. However, in this case, the source of alumina consists of the main raw material in industry, boehmite, largely used for the preparation of alumina catalysts and supports. Pre-formed boehmite nanocrystals were observed which could act as "building blocks" to form the mesostructure with crystalline framework walls. The interactions between boehmite particulates and the surfactant were not strong enough to destroy the intrinsic boehmite crystalline structure, but could effectively direct the loose stacking of the boehmite particulates, leading to mesostructured aluminas with pore sizes of $11 \mathrm{~nm}$ and surface areas of $339 \mathrm{~m}^{2} / \mathrm{g}$. Fulvio et al. [50] came to those conclusions by using the same method. They observed samples with a specific surface area of $300 \mathrm{~m}^{2} / \mathrm{g}$ and pore size of $16 \mathrm{~nm}$, demonstrating better characteristics as crystallinity, thermal stability, etc., than mesoporous aluminas obtained with an alkoxide precursor.

Zhang et al. [51] although also used boehmite as aluminum precursor; the non-ionic surfactant implemented was Tergitol. This led to samples formation with pore diameter of $15 \mathrm{~nm}$ with a specific surface area of $321 \mathrm{~m}^{2} / \mathrm{g}$. In the past, the same group successfully prepared mesoporous aluminas with surface areas of $350 \mathrm{~m}^{2} / \mathrm{g}$ and pore size of $6.7 \mathrm{~nm}$, using several pluronic surfactant types along with different aluminum precursors, such as $\mathrm{AlCl}_{3} \cdot 6 \mathrm{H}_{2} \mathrm{O}, \mathrm{Al}\left(\mathrm{NO}_{3}\right)_{3} \cdot 9 \mathrm{H}_{2} \mathrm{O}$ and aluminum chlorohydrate [52].

Bleta et al. [53] used different quantities of Pluronic F127 to evaluate the influence of the quantity of the polymer in the formation of mesopores. Using aluminum tri-sec-butoxide (ABS) to prepare boehmite colloids, it was observed that the pore size increased up to $14 \mathrm{~nm}$ for an $\mathrm{EO} / \mathrm{Al}$ ratio comprised between 0.6 and 1.2 and a specific surface area of $450 \mathrm{~m}^{2} / \mathrm{g}$, which can be associated to micelles formation. This means, the copolymer adsorbs on boehmite nanoparticles when its concentration is low, but with a higher content in copolymers, the formation of micelles occurred, acting as space fillers, hence preventing the compaction of boehmite nanoparticles.

Other techniques than EISA method can be found in the literature for the preparation of mesoporous aluminas. Taking into account the needs of the material and the resources locally available, they can be considered more or less simple than the method described above. In the following paragraphs, a small overview of those implemented methods is presented.

A green way to produce mesoporous aluminas is presented by Zhang et al. [54] who found a way to use methylcellulose (MC), able to be recovered up to $60 \%$ after the synthesis. The samples prepared by aluminum chloride and sodium aluminate and templated by MC exhibited surface areas of $315 \mathrm{~m}^{2} / \mathrm{g}$ and pore sizes of $8 \mathrm{~nm}$ with an organized mesostructure. Cardoso et al. [55] presented an original strategy to synthesize mesoporous alumina by introduction of biomass. Sugar cane bagasse was hydrolyzed with a strong base, recovering after filtration both the liquid and the solid. The pure bagasse, the hydrolysis of bagasse and the fibers remaining from the hydrolysis step were then mixed with bayerite separately, and subjected to a hydrothermal treatment. After calcination, the samples prepared with fibers from hydrolysis showed lower BET surface area but larger pore diameter than the sample prepared with pristine bagasse. In contrast, the use of biomass hydrolysate had no influence on the structure of alumina. It was then concluded that the presence of biomass (the nature rather than its amount) strongly affected the self-assembly process of the crystals [55].

Kumar et al. [56] investigated the effect of peptization agents, additives and binder on the mesopore size distribution of alumina powder. Boehmite was peptized with nitric acid and added to polyvinyl alcohol, polyethylene glycol, and carbon black. They observed that an increase in the concentration of nitric acid led to diminish the surface area and enhance the pore volume, the optimal concentration being $1.5 \%$. They were able to control the pore size in the range of mesoporosity. 
Polyvinyl alcohol showed to be more effective in the increase of mesopores than polyethylene glycol, although both were able to create macroporosity. Likewise, carbon black raised the mesoporosity, but did not affect the macroporosity.

An important note should be presented here concerning the peptization of boehmite with an acid. It was found that boehmite particles adsorb protons on the surface hydroxyl groups and repel each other to form colloidal particles when the acid/alumina ratio was kept low. Using more hydrochloric acid, large amounts of chloride anions caused compression of the boehmite diffusion layer, resulting in boehmite coalescence. It was then found that an optimum acid/alumina ratio of 0.11 resulted in the smallest dispersed boehmite particles [57].

Deng et al. [58] used Pluronic 64L together with aluminum ABS in butanol giving birth to pore sizes up to $11 \mathrm{~nm}$ and surface areas up to $470 \mathrm{~m}^{2} / \mathrm{g}$. The samples demonstrated thermal stability after template removal, but also after prolonged heating at elevated temperature.

An important study from Yue et al. [59] highlighted the importance of hydroxyl polyacids to enhance the interaction between aluminum species and surfactant, thus promoting the directing function of the template. The procedure consisted of a hydrothermal treatment of $\mathrm{Al}\left(\mathrm{NO}_{3}\right)_{3} \cdot 9 \mathrm{H}_{2} \mathrm{O}$ and $\mathrm{NaAlO}_{2}$ with CTAB and citric acid dissolved in water. Several characterization techniques confirmed that the samples with CTAB or citric acid could not alter the structure of alumina upon the hydrolysis process. The same was observed in another study from the same group [60]. The reason more likely proposed by the authors suggests that CTAB cationic surfactant hardly interacted with neutral aluminum hydroxides. However, in samples subjected to double templating in both studies presented surface areas close to $400 \mathrm{~m}^{2} / \mathrm{g}$ associated with pore sizes up to $6.2 \mathrm{~nm}$.

Su et al. [61] prepared mesoporous alumina with a lamellar structure using sodium aluminate and aluminum sulfate together with polyethylene glycol with an average molar weight of $6000 \mathrm{~g} / \mathrm{mol}$. Samples with specific surface areas of $280 \mathrm{~m}^{2} / \mathrm{g}$ and pore diameters of $12 \mathrm{~nm}$ were obtained with the addition of PEG6000. The authors suggested that the dispersion of the surfactant in a polar medium, the oxide groups form the outer surface of micelles, became in close contact with the polar medium. Then, boehmite crystallites grew in the direction parallel to the corrugated surface due to strong bonding between the oxide group of the surfactant and boehmite surface.

Liu et al. [62] analyzed the introduction of mesopores by adding only hydro-carboxylic acids (HCA) as structure-directing agents. For that, the normal procedure was performed by peptizing boehmite with nitric acid, followed by additional citric acid, or DL-malic acid, tartaric acid, or lactic acid. Samples with specific surface areas up to $380 \mathrm{~m}^{2} / \mathrm{g}$ and pore sizes of $27 \mathrm{~nm}$ calculated by mercury intrusion were obtained. The authors observed different pore structures due to coordination interactions and the steric effect of the HCA.

In principle, these techniques are of easy implementation, but originate relatively small pore sizes and volumes, and specific surface areas. This is due to the fact that the aforementioned methods are very sensitive to the mixture preparation conditions. Moreover, one of the main drawbacks remains the large amount of organics that have to be eliminated resulting in low yields. Table 3 presents a summary of the strategies reported to synthesize ordered mesoporous aluminas.

Table 3. Summary of the techniques used for the synthesis of ordered mesoporous alumina.

\begin{tabular}{|c|c|c|c|c|}
\hline Reference & Al Source & Template & $\begin{array}{c}\text { Surface Area } \\
\left(\mathrm{m}^{2} / \mathrm{g}\right)\end{array}$ & $\begin{array}{l}\text { Pore Diameter } \\
(\mathrm{nm})\end{array}$ \\
\hline [42] & Aluminum salts & Polyethylene glycol 1540 & 300 & 6 \\
\hline$[43,45,47,48]$ & $\begin{array}{l}\text { Aluminum isopropoxide; } \\
\text { aluminum titert-butoxide }\end{array}$ & Pluronic P123 & $261-434$ & $2.9-9.5$ \\
\hline$[44,53]$ & Aluminum isopropoxide & Pluronic F127 & $338-450$ & $8-14$ \\
\hline$[46]$ & Aluminum isopropoxide & Pluronic P123 + trimethylbenzene & 309 & 7.5 \\
\hline$[49,50]$ & Boehmite & Pluronic P123 & $300-339$ & $11-16$ \\
\hline [51] & Boehmite & Tergitol & 321 & 15 \\
\hline [54] & $\begin{array}{l}\text { Aluminum chloride }+ \\
\text { sodium aluminate }\end{array}$ & Methylcellulose & 315 & 8 \\
\hline
\end{tabular}


Table 3. Cont.

\begin{tabular}{|c|c|c|c|c|}
\hline Reference & Al Source & Template & $\begin{array}{c}\text { Surface Area } \\
\left(\mathrm{m}^{2} / \mathrm{g}\right)\end{array}$ & $\begin{array}{l}\text { Pore Diameter } \\
(\mathrm{nm})\end{array}$ \\
\hline [55] & Bayerite & Sugar cane bagasse & 209 & 7.8 \\
\hline [58] & $\begin{array}{l}\text { Aluminum } \\
\text { tri-sec-butoxide }\end{array}$ & Pluronic $64 \mathrm{~L}$ & 470 & 11 \\
\hline$[59,60]$ & Aluminum nitrate & CTAB + hydroxylpolyacids & 400 & 6.2 \\
\hline [61] & $\begin{array}{l}\text { Sodium aluminate }+ \\
\text { aluminum sulphate }\end{array}$ & PEG 6000 & 280 & 12 \\
\hline [62] & Boehmite & Hydro-carboxylic acids & 380 & 27 \\
\hline
\end{tabular}

\subsection{Disordered Mesoporous Aluminas}

If the desired application does not require a well-ordered mesoporous alumina phase, the synthesis of disordered mesoporous materials can be more convenient and efficient. The following method is easily scaled-up, in contrast to the previous synthesis of EISA that requires an expensive structure-directing agent. It consists of a one-step, easy, and fast method to obtain disordered mesoporous $\gamma-\mathrm{Al}_{2} \mathrm{O}_{3}$ by using 2-butoxyethanol as a solvent and as controlling agent for the $\mathrm{Al}(\mathrm{Osec}) \mathrm{Bu}_{3}$ hydrolysis [38]. This method led to designed materials with a crystalline alumina phase with high specific area of $338 \mathrm{~m}^{2} / \mathrm{g}$ and a mesopore size of $11 \mathrm{~nm}$ (Figure 8). Surprisingly, the authors supported that this method provides better yields as only $30 \%$ of the raw materials consist of inorganics needed to be eliminated during the calcination process.

A different template can be used for mesoporosity generation in aluminas as suggested by $\mathrm{Xu}$ et al. [63]. Indeed, glucose was chosen as structure-directing agent upon the hydrolysis of aluminum isopropoxide, yielding specific areas of $422 \mathrm{~m}^{2} / \mathrm{g}$ and pore size of $5.1 \mathrm{~nm}$. TEM analysis showed a wormhole-like appearance, but no significant pore ordering. XRD patterns confirmed the amorphous nature of the samples calcined at $600{ }^{\circ} \mathrm{C}$. It was necessary to raise the temperature up to $800{ }^{\circ} \mathrm{C}$ to evidence mesoporous $\gamma-\mathrm{Al}_{2} \mathrm{O}_{3}$, thus showing that the thermal stability of mesoporous alumina by this method is very high.

A study performed by Bejenaru et al. [48] evaluated several techniques for a proper introduction of mesopores in alumina that could be used as supports for CoMo HDS catalysts. One of the techniques was the sol-gel method, where tri-sec-butoxide was dissolved in 2-butanol with further addition of butan-1,3-diol. After evaporation of the solvent and calcination of the samples, a specific surface area of $349 \mathrm{~m}^{2} / \mathrm{g}$ and pore size of $10.7 \mathrm{~nm}$ were achieved. Another strategy consisted of using a cationic surfactant that could be mixed to aluminum-tri-sec-butoxide dissolved in ethanol with CTAB, or aluminum nitrate and P123, or aluminum-trisec-butoxide with P123 together with butanol. All the samples exhibited a disordered mesostructure with specific surface areas ranging between 343 and $423 \mathrm{~m}^{2} / \mathrm{g}$ associated to pore sizes between 5.3 and $11.6 \mathrm{~nm}$. Table 4 summarizes the different approaches selected to produce disordered mesoporous aluminas.

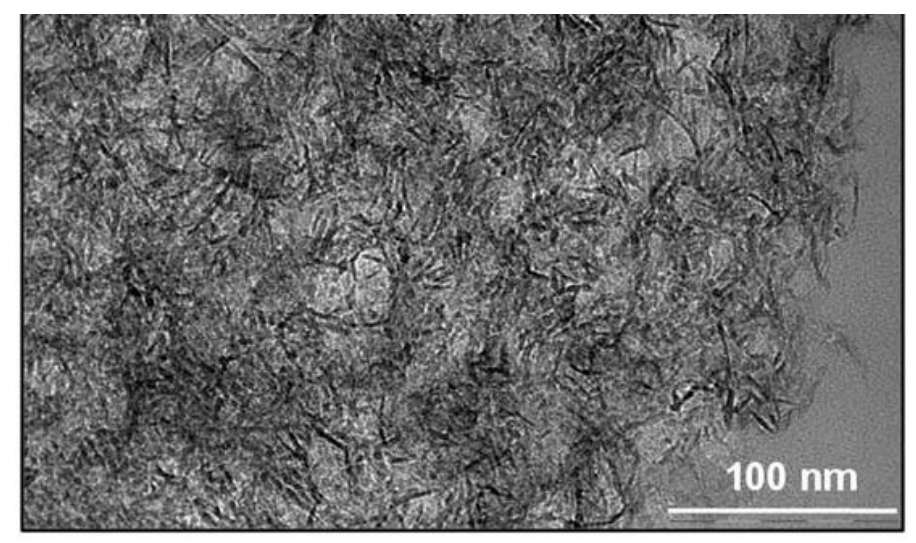

Figure 8. Disordered mesoporous alumina prepared by Hartmann et al. [38]. 
Table 4. Summary of the strategies to design disordered mesoporous aluminas.

\begin{tabular}{ccccc}
\hline Reference & Al Source & Method & Surface Area $\left(\mathbf{m}^{2} / \mathbf{g}\right)$ & Pore Diameter $(\mathbf{n m})$ \\
\hline$[38]$ & Aluminum tri-sec-butoxide & Sol-gel & 338 & 11 \\
{$[63]$} & Aluminum isopropoxide & Glucose templating & 422 & 5.1 \\
{$[48]$} & Aluminum tri-sec-butoxide & Sol-gel & 349 & 10.7 \\
\hline
\end{tabular}

\subsection{Macrostructured Aluminas}

In this last section, few methods for the preparation of hierarchical macro-/mesoporous aluminas are presented. Materials with macropores possess the advantage to allow high mass transfer with low pressure drop and high specific surface areas for a good dispersion of the active sites. For example, Dacquin et al. [64] discovered a route to design highly-organized macro-mesoporous aluminas. For that, pure mesoporous aluminas were prepared according to an EISA procedure using Pluronic P123. This strategy yielded a well-resolved hexagonal pore structure with pore sizes of $5.1 \mathrm{~nm}$. To obtain macroporous-mesoporous solids, monodispersed latex spheres of controlled size were added to the former solution. From SEM analysis, it was possible to observe a long-range structural ordering imparted by a polystyrene template resulting in a macroporous skeleton with macropores of $320 \mathrm{~nm}$ and a specific surface area of $249 \mathrm{~m}^{2} / \mathrm{g}$. However, XRD analysis did not evidence any crystalline alumina phase. This suggests that the framework comprised transitional alumina between hydroxide or oxyhydroxide and $\gamma-\mathrm{Al}_{2} \mathrm{O}_{3}$.

Li et al. [65] found a way to prepare highly-ordered 2D hexagonal mesopores in the walls of macroporous materials. The general synthesis strategy was based on a simple sol-gel process using the polyurethane (PU) foam replication method combined with P123 as the mesoporous structure-directing agent. For that, aluminum isopropoxide, nitric acid, and P123 were dissolved in ethanol. After the addition of PU, the sol solution entered into interconnected macropore voids by capillary and wetting driving forces. Then the cross-linked aluminum species could assemble with P123 to form ordered mesophases on the inner surface of the PU, resulting in a solvent-evaporation-induced coating and self-assembly process. The samples exhibited mesopores of $3.4 \mathrm{~nm}$, macropores of $600 \mu \mathrm{m}$ and specific surface area of $300 \mathrm{~m}^{2} / \mathrm{g}$ (Figure 9). Through the same sol-gel method, Tokudome et al. $[66,67]$ investigated the formation of meso-macroporous $\mathrm{Al}_{2} \mathrm{O}_{3}$ monoliths from aerogels and xerogels in the presence of propylene oxide and poly(ethylene oxide) (PEO). Indeed, they observed that samples with different PEO content can lead to a tailored range of pores ranging from $400 \mathrm{~nm}$ to $1.8 \mu \mathrm{m}$. This is caused by the distribution of PEO in the fluid phase that turns into macropores after drying. Moreover, these macrostructures are formed as a result of phase separation, while the interstices between the secondary particles of the gel skeletons work as mesopore structures. Samples with surface area up to $511 \mathrm{~m}^{2} / \mathrm{g}$ and mesopores of 5.4-33.1 nm were produced, depending on the type of gel used; aerogel versus xerogel.

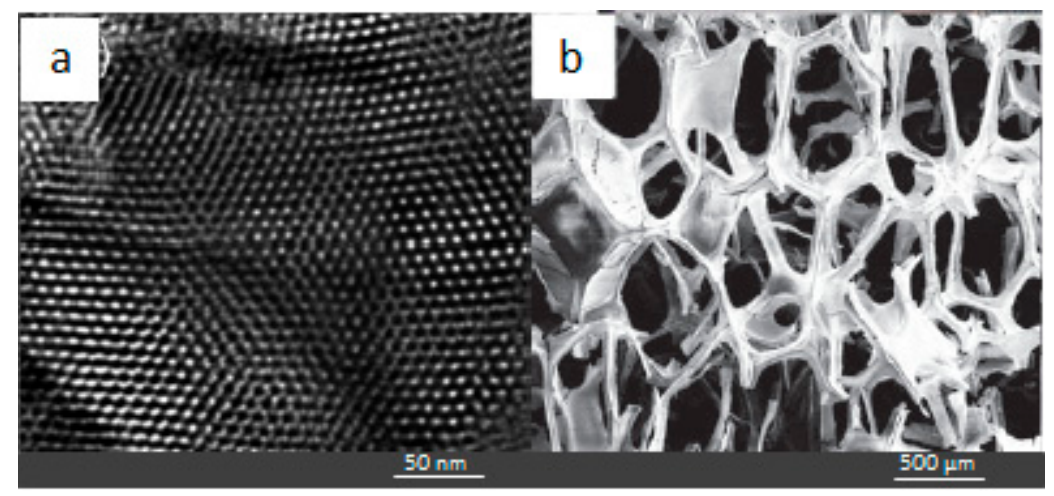

Figure 9. (a) Ordered mesoporous walls of the materials obtained by TEM; (b) macropores of the material visible by SEM. Samples obtained by Li et al. [65]. 
Finally, Ma et al. [68] proposed the use of bio-templates to form meso-macroporous aluminas. The template used in the study was a yeast aqueous solution added to a solution of $\mathrm{Al}\left(\mathrm{NO}_{3}\right)_{3} \cdot 9 \mathrm{H}_{2} \mathrm{O}$ and triethanolamine. SEM images showed a macroporous structure with pore sizes between $1.5-3 \mu \mathrm{m}$, whose walls were impregnated by mesopores between $3-4.5 \mathrm{~nm}$ as determined by $\mathrm{N}_{2}$ adsorption/desorption isotherms, also giving birth to surface area values of about $340 \mathrm{~m}^{2} / \mathrm{g}$. A raise in the calcination temperature hardly increased the quantity of mesopores, suggesting a structure with high thermal stability. Table 5 summarizes the strategies encountered to design macroporous alumina materials.

Table 5. Strategies undertaken for the synthesis of macroporous alumina.

\begin{tabular}{ccccc}
\hline Reference & Al Source & Template & $\begin{array}{c}\text { Surface Area } \\
\left(\mathbf{m}^{2} / \mathbf{g}\right)\end{array}$ & $\begin{array}{c}\text { Pore Diameter } \\
(\boldsymbol{\mu m})\end{array}$ \\
\hline$[64]$ & Aluminium isopropoxide & Latex spheres & 249 & 0.3 \\
{$[65]$} & Aluminium isopropoxide & Polyurethane foam & 300 & 600 \\
{$[66,67]$} & Aluminium chloride & Poly(ethylene oxide) & 511 & $0.4-1.8$ \\
{$[68]$} & Aluminium nitrate & Yeast & 340 & $1.5-3$ \\
\hline
\end{tabular}

\section{Conclusions}

The application of zeolites in industry involves several a priori processes of preparation, such as shaping, in order to take the maximum potential of these kaleidoscopic-purposes catalysts. Each one of these syntheses leads to modifications that can influence both zeolite textural properties and their catalytic performance. Many researchers are applying significant efforts to minimize these aspects, taking into account the simplicity and the cost required upon scaling-up.

Although several binders have been proposed, up to now silica and alumina remain the most commonly used in industry due to their low cost and simplicity for the process of extrusion. However, several aspects were observed, both negative and positive, in zeolitic systems. As the use of binders remains, until now, a pre-requisite for industrial reactors, the challenge remains to find a way to overcome the drawbacks brought by these materials, especially concerning the influence in the acidity of the catalytic body and in the textural properties of the zeolite.

A strategy was presented in this mini-review to solve the last drawback by the introduction of hierarchical porosity in the binder. This process has the potential to minimize its influence in the surface area and micropore volume of the zeolite, leading to better mass transfer, resulting in a catalytic activity similar to the powder form. In an optimistic case, one may also expect to improve either the selectivity or the catalyst life-time.

For that, as it was described, there is the possibility to introduce different porosities that can be chosen according to the requirements of the reaction. However, one need to take into account the influence of those modifications on the mechanical strength of the catalytic body, a feature that demands the use of binders at the first place.

Conflicts of Interest: The authors declare no conflict of interest.

\section{References}

1. Cronstedt, A.F. Rön Och Beskrifning om en Obekant Bärg Art, Som Kallas Zeolites; Akad.Handl.Stockholm: Tokyo, Japan, 1756; Volume 18, pp. 120-130.

2. Colella, C.; Gualtieri, A.F. Cronstedt's zeolite. Microporous Mesoporous Mater. 2007, 105, 213-221. [CrossRef]

3. Loewenstein, $\mathrm{W}$. The distribution of aluminum in the tetrahedra of silicates and aluminates. Am. Mineral. 1954, 39, 92-96.

4. Losch, P.; Boltz, M.; Soukup, K.; Song, I.H.; Yun, H.S.; Louis, B. Binderless zeolite coatings on macroporous $\alpha-\mathrm{SiC}$ foams. Microporous Mesoporous Mater. 2014, 188, 99-107. [CrossRef] 
5. Ertl, G.; Knözinger, H.; Schüth, F.; Weitkamp, J. Physical Properties-Microporosity. In Handbook Heterogeneous Catalysis, 2nd ed.; Wiley VCH: Weinheim, Germany, 2009; Volume 1, p. 729.

6. Baerlocher, C.; McCusker, L.B. Database of Zeolite Structures. Available online: http:/ /www.iza-structure. org/databases / (accessed on 16 January 2018).

7. Perego, C.; Bassi, G.; Girotti, G. Extruded Catalyst Based on Silica/Alumina Gel. European Patent 0665055 A1, 23 January 1995.

8. Chu, P.; Garwood, W. Catalytic Composition from Reaction of High Silica Zeolites with Binder. U.S. Patent 4,563,435, 23 June 1982.

9. Martin, A.; Berndt, H.; Lohse, U.; Wolf, U. Effect of Si:Al ratio and type of binder on the catalytic properties of HZSM-5 catalysts. J. Chem. Soc. Faraday Trans. 1993, 89, 1277-1282. [CrossRef]

10. Wu, X.; Alkhawaldeh, A.; Anthony, R.G. Investigation on acidity of zeolites bound with silica and alumina. Stud. Surf. Sci. Catal. 2002, 143, 217-225.

11. Liu, G.; Guo, J.; Meng, F.; Zhang, X.; Wang, L. Effects of colloidal silica binder on catalytic activity and adhesion of HZSM-5 coatings for structured reactors. Chin. J. Chem. Eng. 2014, 22, 875-881. [CrossRef]

12. Lee, K.Y.; Lee, H.K.; Ihm, S.K. Influence of catalyst binders on the acidity and catalytic performance of HZSM-5 zeolites for methanol-to-propylene (MTP) process: Single and binary binder system. Top. Catal. 2010, 53, 247-253. [CrossRef]

13. Kasture, M.W.; Niphadkar, P.S.; Bokade, V.V.; Joshi, P.N. On the catalytic performance in isopropylation of benzene over $\mathrm{H} / \beta$ zeolite catalysts: Influence of binder. Catal. Commun. 2007, 8, 1003-1008. [CrossRef]

14. Kong, X.; Liu, J. Influence of alumina binder content on catalytic performance of Ni/HZSM-5 for hydrodeoxygenation of cyclohexanone. PLoS ONE 2014, 9, 5-10. [CrossRef] [PubMed]

15. Du, X.; Kong, X.; Chen, L. Influence of binder on catalytic performance of Ni/HZSM-5 for hydrodeoxygenation of cyclohexanone. Catal. Commun. 2014, 45, 109-113. [CrossRef]

16. Pérez-Uriarte, P.; Gamero, M.; Ateka, A.; Diaz, M.; Aguayo, A.T.; Bilbao, J. Effect of the acidity of HZSM-5 zeolite and the binder in the DME transformation to olefins. Ind. Eng. Chem. Res. 2016, 55, 1513-1521. [CrossRef]

17. Chen, D.; He, L.; Shang, S. Study on aluminum phosphate binder and related $\mathrm{Al}_{2} \mathrm{O}_{3}-\mathrm{SiC}$ ceramic coating. Mater. Sci. Eng. A 2003, 348, 29-34. [CrossRef]

18. Lee, Y.J.; Kim, Y.W.; Viswanadham, N.; Jun, K.W.; Bae, W.J. Novel aluminophosphate (AlPO) bound ZSM-5 extrudates with improved catalytic properties for methanol to propylene (MTP) reaction. Appl. Catal. A Gen. 2010, 374, 18-25. [CrossRef]

19. Freiding, J.; Patcas, F.C.; Kraushaar-Czarnetzki, B. Extrusion of zeolites: Properties of catalysts with a novel aluminium phosphate sintermatrix. Appl. Catal. A Gen. 2007, 328, 210-218. [CrossRef]

20. Freiding, J.; Kraushaar-Czarnetzki, B. Novel extruded fixed-bed MTO catalysts with high olefin selectivity and high resistance against coke deactivation. Appl. Catal. A Gen. 2011, 391, 254-260. [CrossRef]

21. Whiting, G.T.; Meirer, F.; Mertens, M.M.; Bons, A.J.; Weiss, B.M.; Stevens, P.A.; de Smit, E.; Weckhuysen, B.M. Binder Effects in $\mathrm{SiO}_{2}$-and $\mathrm{Al}_{2} \mathrm{O}_{3}$-Bound Zeolite ZSM-5-Based Extrudates as Studied by Microspectroscopy. ChemCatChem 2015, 7, 1312-1321. [CrossRef] [PubMed]

22. Bowes, E. Extrusion of Silica-Rich Solids. U.S. Patent 4,582,815, 15 April 1986.

23. Ghosh, A.; Mihut, C.; Simmons, M. Method of Forming Zeolite Shaped Body with Silica Binder. U.S. Patent 9,180,441 B2, 10 November 2015.

24. Keville, K.; Timken, H.; Ware, R. Method for Preparing Catalysts Comprising Zeolites Extruded with an Alumina Binder. U.S. Patent 5,500,109, 19 March 1996.

25. Plee, D. Zeolite Granules with Zeolitic Binder. U.S. Patent 5,132,260, 21 July 1992.

26. Timken, H. Method for Preparing Titania-Bound Zeolite Catalysts. U.S. Patent 5,430,000, 4 July 1995.

27. Verduijn, J. Process for Producing Substantially Binder-Free Zeolit. U.S. Patent 5,460,769, 24 October 1995.

28. Sun, H.; Shen, B.; Liu, J. N-Paraffins adsorption with 5A zeolites: The effect of binder on adsorption equilibria. Sep. Purif. Technol. 2008, 64, 135-139. [CrossRef]

29. Zhang, J.; Mao, Y.; Li, J.; Wang, X.; Xie, J.; Zhou, Y.; Wang, J. Ultrahigh mechanically stable hierarchical mordenite zeolite monolith: Direct binder-/template-free hydrothermal synthesis. Chem. Eng. Sci. 2015, 138, 473-481. [CrossRef]

30. Jasra, R.V.; Tyagi, B.; Badheka, Y.M.; Choudary, V.N.; Bhat, T.S.G. Effect of clay binder on sorption and catalytic properties of zeolite pellets. Ind. Eng. Chem. Res. 2003, 42, 3263-3272. [CrossRef] 
31. Dorado, F.; Romero, R.; Caizares, P. Hydroisomerization of n-butane over Pd/HZSM-5 and Pd/H $\beta$ with and without binder. Appl. Catal. A Gen. 2002, 236, 235-243. [CrossRef]

32. De Lucas, A.; Valverde, J.L.; Sánchez, P.; Dorado, F.; Ramos, M.J. Influence of the binder on the n-octane hydroisomerization over palladium-containing zeolite catalysts. Ind. Eng. Chem. Res. 2004, 43, 8217-8225. [CrossRef]

33. Sánchez, P.; Dorado, F.; Fúnez, A.; Jiménez, V.; Ramos, M.J.; Valverde, J.L. Effect of the binder content on the catalytic performance of beta-based catalysts. J. Mol. Catal. A Chem. 2007, 273, 109-113. [CrossRef]

34. Shams, K.; Mirmohammadi, S.J. Preparation of 5A zeolite monolith granular extrudates using kaolin: Investigation of the effect of binder on sieving/adsorption properties using a mixture of linear and branched paraffin hydrocarbons. Microporous Mesoporous Mater. 2007, 106, 268-277. [CrossRef]

35. Uphade, B.; Gopal, S. Zeolite-Binder Catalyst Composition. U.S. Patent 2010/0029999 A1, 4 February 2010.

36. Lee, H.J.; Kim, J.H.; Park, D.W.; Cho, S. Effect of base binder, flash calcined hydrotalcite, in MFI zeolite granule: Catalytic activity over 1-butene isomerization and MTO reaction. Appl. Catal. A Gen. 2015, 502, 42-47. [CrossRef]

37. Bazer-Bachi, D.; Harbuzaru, B.; Lecolier, E. Zeolite Formed by Extrusion and Pelleting with a Hydraulic Binder Having Improved Mechanical Properties and Process and Preparing Same. U.S. Patent 2016/0288109A1, 18 November 2010.

38. Hartmann, S.; Sachse, A.; Galarneau, A. Challenges and strategies in the synthesis of mesoporous alumina powders and hierarchical alumina monoliths. Materials 2012, 5, 336-349. [CrossRef] [PubMed]

39. Trueba, M.; Trasatti, S.P. $\gamma$-Alumina as a support for catalysts: A review of fundamental aspects. Eur. J. Inorg. Chem. 2005, 17, 3393-3403. [CrossRef]

40. Yang, H.; Coombs, N.; Sokolov, I.; Ozin, G.A. Free-standing and oriented mesoporous silica films grown at the air-water interface. Nature 1996, 381, 589-592. [CrossRef]

41. Lu, Y.; Fan, H.; Stump, A.; Ward, T.L.; Rieker, T.; Brinker, C.J. Aerosol-assisted self-assembly of mesostructured spherical nanoparticles. Nature 1999, 398, 223-226. [CrossRef]

42. Zhao, R.; Guo, F.; Hu, Y.; Zhao, H. Self-assembly synthesis of organized mesoporous alumina by precipitation method in aqueous solution. Microporous Mesoporous Mater. 2006, 93, 212-216. [CrossRef]

43. Yuan, Q.; Yin, A.X.; Luo, C.; Sun, L.D.; Zhang, Y.W.; Duan, W.T.; Liu, H.C.; Yan, C.H. Facile synthesis for ordered mesoporous $\gamma$-aluminas with high thermal stability. J. Am. Chem. Soc. 2008, 130, 3465-3472. [CrossRef] [PubMed]

44. Grant, S.M.; Vinu, A.; Pikus, S.; Jaroniec, M. Adsorption and structural properties of ordered mesoporous alumina synthesized in the presence of F127 block polymer. Colloids Surf. A Physicochem. Eng. Asp. 2011, 385, 121-125. [CrossRef]

45. Wu, W.; Wan, Z.; Chen, W.; Yang, H.; Zhang, D. A facile synthesis strategy for structural property control of mesoporous alumina and its effect on catalysis for biodiesel production. Adv. Powder Technol. 2014, 25, 1220-1226. [CrossRef]

46. Wu, Q.; Zhang, F.; Yang, J.; Li, Q.; Tu, B.; Zhao, D. Synthesis of ordered mesoporous alumina with large pore sizes and hierarchical structure. Microporous Mesoporous Mater. 2011, 143, 406-412. [CrossRef]

47. Yuan, X.; Xu, S.; Lü, J.; Yan, X.; Hu, L.; Xue, Q. Facile synthesis of ordered mesoporous $\gamma$-alumina monoliths via polymerization-based gel-casting. Microporous Mesoporous Mater. 2011, 138, 40-44. [CrossRef]

48. Bejenaru, N.; Lancelot, C.; Blanchard, P.; Lamonier, C.; Rouleau, L.; Payen, E.; Dumeignil, F.; Royer, S. Synthesis, characterization, and catalytic performances of novel CoMo hydrodesulfurization catalysts supported on mesoporous aluminas. Chem. Mater. 2009, 21, 522-533. [CrossRef]

49. Liu, Q.; Wang, A.; Wang, X.; Gao, P.; Wang, X.; Zhang, T. Synthesis, characterization and catalytic applications of mesoporous $\gamma$-alumina from boehmite sol. Microporous Mesoporous Mater. 2008, 111, 323-333. [CrossRef]

50. Fulvio, P.F.; Brosey, R.I.; Jaroniec, M. Synthesis of mesoporous alumina from boehmite in the presence of triblock copolymer. ACS Appl. Mater. Interfaces 2010, 2, 588-593. [CrossRef] [PubMed]

51. Zhang, Z.; Pinnavaia, T.J. Mesoporous $\gamma$-alumina formed through the surfactant-mediated scaffolding of peptized pseudoboehmite nanoparticles. Langmuir 2010, 26, 10063-10067. [CrossRef] [PubMed]

52. Zhang, Z.; Pinnavaia, T.J. Mesostructured $\gamma-\mathrm{Al}_{2} \mathrm{O}_{3}$ with a lathlike framework morphology. J. Am. Chem. Soc. 2002, 41, 12294-12301. [CrossRef] 
53. Bleta, R.; Alphonse, P.; Pin, L.; Gressier, M.; Menu, M.-J. An efficient route to aqueous phase synthesis of nanocrystalline $\gamma-\mathrm{Al}_{2} \mathrm{O}_{3}$ with high porosity: From stable boehmite colloids to large pore mesoporous alumina. J. Colloid Interface Sci. 2012, 367, 120-128. [CrossRef] [PubMed]

54. Zhang, Y.; Zhong, L.; Chen, F.; Zhang, Y. Synthesis of mesoporous alumina using a recyclable methylcellulose template. Microporous Mesoporous Mater. 2011, 142, 740-744. [CrossRef]

55. Cardoso, C.S.; Licea, Y.E.; Huang, X.; Willinger, M.; Louis, B.; Pereira, M.M. Improving textural properties of $\gamma$-alumina by using second generation biomass in conventional hydrothermal method. Microporous Mesoporous Mater. 2015, 207, 134-141. [CrossRef]

56. Kumar, M.; Lal, B.; Singh, A.; Saxena, A.K.; Dangwal, V.S.; Sharma, L.D.; Dhar, G.M. Control of mesoporosity in alumina. Indian J. Chem. Technol. 2001, 8, 157-161.

57. Zheng, Y.; Song, J.; Xu, X.; He, M.; Wang, Q.; Yan, L. Peptization Mechanism of Boehmite and Its Effect on the Preparation of a Fluid Catalytic Cracking Catalyst. Ind. Eng. Chem. Res. 2014, 53, 10029-10034. [CrossRef]

58. Deng, W.; Bodart, P.; Pruski, M.; Shanks, B.H. Characterization of mesoporous alumina molecular sieves synthesized by nonionic templating. Microporous Mesoporous Mater. 2002, 52, 169-177. [CrossRef]

59. Yue, M.B.; Jiao, W.Q.; Wang, Y.M.; He, M.Y. CTAB-directed synthesis of mesoporous $\gamma$-alumina promoted by hydroxy polyacids. Microporous Mesoporous Mater. 2010, 132, 226-231. [CrossRef]

60. Yue, M.B.; Xue, T.; Jiao, W.Q.; Wang, Y.M.; He, M.Y. CTAB-directed synthesis of mesoporous $\gamma$-alumina promoted by hydroxy carboxylate: The interplay of tartrate and CTAB. Solid State Sci. 2011, 13, 409-416. [CrossRef]

61. Su, A.P.; Zhou, Y.; Yao, Y.H.; Yang, C.M.; Du, H. A facile rout to synthesis lamellate structure mesoporous alumina using polyethylene glycol $6000(\mathrm{PEG}$, molecular weight $=6000)$ as structure directing agent. Microporous Mesoporous Mater. 2012, 159, 36-41. [CrossRef]

62. Liu, Q.; Wang, A.; Wang, X.; Zhang, T. Mesoporous $\gamma$-alumina synthesized by hydro-carboxylic acid as structure-directing agent. Microporous Mesoporous Mater. 2006, 92, 10-21. [CrossRef]

63. Xu, B.; Xiao, T.; Yan, Z.; Sun, X.; Sloan, J.; González-Cortés, S.L.; Alshahrani, F.; Green, M.L.H. Synthesis of mesoporous alumina with highly thermal stability using glucose template in aqueous system. Microporous Mesoporous Mater. 2006, 91, 293-295. [CrossRef]

64. Dacquin, J.P.; Dhainaut, J.; Duprez, D.; Royer, S.; Lee, A.F.; Wilson, K. An efficient route to highly organized, tunable macroporous- mesoporous alumina. J. Am. Chem. Soc. 2009, 131, 12896-12897. [CrossRef] [PubMed]

65. Li, L.-L.; Duan, W.-T.; Yuan, Q.; Li, Z.-X.; Duan, H.-H.; Yan, C.-H. Hierarchical $\gamma-\mathrm{Al}_{2} \mathrm{O}_{3}$ monoliths with highly ordered 2D hexagonal mesopores in macroporous walls. Chem. Commun. 2009, 6174-6176. [CrossRef] [PubMed]

66. Tokudome, Y.; Fujita, K.; Nakanishi, K.; Miura, K.; Hirao, K. Synthesis of monolithic $\mathrm{Al}_{2} \mathrm{O}_{3}$ with well-defined macropores and mesostructured skeletons via the sol-gel process accompanied by phase separation. Chem. Mater. 2007, 13, 3393-3398. [CrossRef]

67. Tokudome, Y.; Nakanishi, K.; Kanamori, K.; Fujita, K.; Akamatsu, H.; Hanada, T. Structural characterization of hierarchically porous alumina aerogel and xerogel monoliths. J. Colloid Interface Sci. 2009, 338, 506-513. [CrossRef] [PubMed]

68. Ma, Y.; Wei, Q.; Ling, R.; An, F.; Mu, G.; Huang, Y. Synthesis of macro-mesoporous alumina with yeast cell as bio-template. Microporous Mesoporous Mater. 2013, 165, 177-184. [CrossRef]

(C) 2018 by the authors. Licensee MDPI, Basel, Switzerland. This article is an open access article distributed under the terms and conditions of the Creative Commons Attribution (CC BY) license (http://creativecommons.org/licenses/by/4.0/). 